\title{
Questions Surrounding iPS Cells in Japan
}

\author{
Yoshiki Yui
}

iPS cells represent marked progress in regenerative medicine. However, recently, I have considered the following three problems regarding iPS cell research in Japan.

\section{Treatment of Age-related Macular Degeneration Using iPS Cells}

Two years ago, the first clinical application study of iPS cells began with age-related macular degeneration. At first, six cases were scheduled. However, last year, for the second patient, the operation was stopped due to the genetic mutation of iPS cells from this patient.

This genetic mutation was reported to be the absence of some genetic information. The risk of developing cancer also could not be excluded. The carcinogenicity of iPS cells, therefore, remains unresolved.

It appears that from now, instead of using costly and time-consuming iPS cells from each patient, stocked iPS cells from healthy donors with homozygous HLA (human leukocyte antigen), for which the safety is checked beforehand, are going to be used. In regard to this, I have some misgivings. In the first place, the superiority of iPS cells over ES cells is that one can use the patient's own cells (tissue), which does not carry the risk of the rejection and resolves ethical issues.

As previously planned, I think the remaining five patients should be operated on using the patients' own cells. The cost and time is not an issue only for these five

\footnotetext{
Accepted for publication April 21, 2016, Published online May 30, 2016 Correspondence to Yoshiki Yui

Formerly affiliated with Department of Cardiology, Kyoto University Hospital, 54 Kawaharachou, Shogoin, Sakyoku, Kyoto 6068397, Japan

Tel: +81-75-751-3111

E-mail: yoshikibmw@gmail.com \& yoshiki@kuhp.kyoto-u.ac.jp

(c) This is an open-access article distributed under the terms of the Creative Commons Attribution Non-Commercial License (http://creativecommons.org/ licenses/by-nc/4.0/), which permits unrestricted non-commercial use, distribution, and reproduction in any medium, provided the original work is properly cited.
}

patients. On obtaining successful results and experiences with these six patients, as the next step, stocked iPS cells should be applied carefully. The phrase "Make haste slowly" comes to my mind. Is this a groundless concern by a non-professional layperson?

\section{iPS Cells and Muse cells}

A Tohoku University group found Muse cells $(1,2)$. They claimed that iPS cells were created only from Muse cells in fibroblasts (human skin), and that iPS cells were not created from non-Muse cells. Four genes including the oncogene were forcibly introduced into Muse cells, which produced iPS cells. They insisted that Muse cells without differentiation induction have no carcinogenicity. Have their assertions reached a consensus? At present, Muse cells are also being studied for clinical application. Recently, interesting research was reported.

Damaged brain tissue caused by infarction in the rat was effectively repaired by the infusion of Muse cells (3). Muse cells are considered to have homed to the infarcted site. In 2007, iPS cells were also induced from adult human fibroblasts (skin) (4). iPS cells and Muse cells are both from human skin fibroblasts. I wonder whether these cells are completely different and unrelated. Are iPS cells derived from Muse cells (at least in fibroblasts) as the Tohoku University group assert? This issue should be resolved scientifically, which may contribute to the progress in cell biology for regenerative medicine.

\section{The Same Standard Deviation (SD)}

There has been a statistical concern that eight standard deviations (SD) in the comparative study in Figure $7 \mathrm{~B}$, right in EMBO-J (5) were similar.

The paper reported that NAT1 plays an important role in ES cell differentiation. This paper is the basis for iPS cells. In April 2014, in response to this, the board of investigation of CiRA (Center for iPS Cell Research and Application, Kyoto University) announced that the mean 
and SD recalculated from Director Yamanaka's experiment record corresponding to Fig. 7B, right were different from those of the paper (https://www.cira.kyotou.ac.jp/ $\mathrm{j} /$ pressrelease/other/140428-192654.html).

However, the investigation seems to have stopped at that point.

In Fig. 7B, left, it looks natural that SD varies, but this data (Fig. 7B, right) looks quite strange to me. I wonder if the same eight SD can be reproducible again. SD is an important statistical parameter when evaluating data. I pointed out the same mean and SD abnormality in Valsartan (Diovan) hypertensive studies, which had led to a revelation of misconducts $(6,7)$.

Keywords: iPS cells, carcinogenicity, Muse cells, standard deviation

\section{Potential conflict of interest}

The author has no conflicting financial interest.

\section{References}

1. Kuroda Y, Kitada M, Wakao S, Nishikawa K, Tanimura Y, Makinoshima H, Goda M, Akashi H, Inutsuka A, Niwa A, Shigemoto T, Nabeshima Y, Nakahata T, Nabeshima Y,
Fujiyoshi Y, Dezawa M. Unique multipotent cells in adult human mesenchymal cell populations. Proc Natl Acad Sci USA 2010;107:8639-8643

2. Wakao S, Kitada M, Kuroda Y, Shigemoto T, Matsuse D, Akashi H, Tanimura Y, Tsuchiyama K, Kikuchi T, Goda M, Nakahata T, Fujiyoshi Y, Dezawa M. Multilineage-differentiating stress-enduring (Muse) cells are a primary source of induced pluripotent stem cells in human fibroblasts. Proc Natl Acad Sci USA 2011;108:9875-9880

3. Uchida H, Morita T, Niizuma K, Kushida Y, Kuroda Y, Wakao S, Sakata H, Matsuzaka Y, Mushiake H, Tominaga T, Borlongan CV, Dezawa M. Transplantation of unique subpopulation of fibroblasts, muse cells, ameliorates experimental stroke possibly via robust neuronal differentiation. Stem Cells 2016;34:160-173

4. Takahashi K, Tanabe K, Ohnuki M, Narita M, Ichisaka T, Tomoda K, Yamanaka S. Induction of pluripotent stem cells from adult human fibroblasts by defined factors. Cell 2007;131:861-872

5. Yamanaka S, Zhang XY, Maeda M, Miura K, Wang S, Farese RV Jr, Iwao H, Innerarity TL. Essential role of NAT1/p97/DAP5 in embryonic differentiation and the retinoic acid pathway. EMBO J 2000;19:5533-5541

6. Yui Y. Concerns about the Jikei heart study. Lancet 2012;379:e48

7. Yui Y. Prevention of misconduct in clinical trials in Japan. Lancet 2014;384:1098 